\title{
Relationship of Acromial Morphology and Rotator Cuff Integrity
}

\section{Mohammed El Idrissi*, Abdelhalim Elibrahimi, Abdelmajid EImrini}

Department of Orthopeadic Surgery B4, Hassan II University Hospital, Fez, Morocco

Email address:

elidrimed@gmail.com (M. El Idrissi)

${ }^{*}$ Corresponding author

\section{To cite this article:}

Mohammed El Idrissi, Abdelhalim Elibrahimi, Abdelmajid Elmrini. Relationship of Acromial Morphology and Rotator Cuff Integrity. International Journal of Clinical and Experimental Medical Sciences. Vol. 3, No. 6, 2017, pp. 78-81. doi: 10.11648/j.ijcems.20170306.13

Received: May 11, 2017; Accepted: May 22, 2017; Published: November 28, 2017

\begin{abstract}
The influence of individual acromial morphology on the pathogenesis of rotator cuff tears remains controversial. Since Neer first described the impingement syndrome, several authors have described the morphology of the acromion. In this study, we try to find a physiopathological correlation between the anatomical morphology of the acromion based on these two recently descripted parameters (Acromial index and Critical Shoulder Angle) and rotator cuff tears. Thirty-six consecutive conventional rotator cuff repair patients were retrospectively reviewed at our institution. Standardized, true anteroposterior radiographs with the arm in the neutral position were used to assess the acromion index, and the critical shoulder angle according. On standardized outlet views, the acromion morphology was classified according to Bigliani and Morrison. The acromion was flat in 2 patients (6\%), curve (type 2) in eight patients, and hooked. The mean acromial index was 0.7 . The mean critical shoulder angle was $37^{\circ}$. Acromial morphology plays without any doubt an important role in the pathogenesis impingement and its evolution to cuff rotator tears. The results of our study confirm the importance of a more comprehensive evaluation of the morphology of the acromion, which take in consideration not only acromial shape, but especially its lateral extension evaluated by the acromial index and the critical angle of the shoulder.
\end{abstract}

Keywords: Acromion Index, Critical Shoulder Angle, Rotator Cuff Tears

\section{Introduction}

Impingement syndrome and rotator cuff tears have been related to the morphology of the acromion. Since Neer [1] first described the impingement syndrome in 1972, several authors have described the morphology of an acromion, with regards to its shape [2], anterior slope [3], lateral acromion angle [4], and relationship with rotator cuff integrity. Recently, Nyffeler et al. [5] introduced an acromion index (AI) as a new biomechanical value and hypothesized that a large lateral extension of an acromion predisposes the supraspinatus tendon to degenerate because of its impingement between an acromion and the higher ascending force of a deltoid muscle. Moor et al. [6] described another parameter which quantifies the extent of acromial cover and the inclination of the glenoid without being influenced by a flattening of the humeral head or excessive bony erosion of the posterior of the glenoid and they called it the critical shoulder angle (CSA). In this study, we try to find a physiopathological correlation between the anatomical morphology of the acromion based on these two parameters (IA and CSA) and rotator cuff tears.

\section{Method}

\subsection{Patient Selection}

Thirty-six consecutive conventional rotator cuff repair patients were retrospectively reviewed at our institution. We included patients with available preoperative true anteroposterior and standardized lateral (outlet) views. Patients with inflammatory disease or a history of trauma or previous surgery were excluded. There were 26 men and 10 women (ratio sex: 2.5). The mean age was 53 years [27-80].

\subsection{Radiologic Assessment}

Standardized, true anteroposterior radiographs with the 
arm in the neutral position were used to assess the acromion index (AI) as described by Nyffeler et al. [5] (Figure 1), and the critical shoulder angle according to Moor et al. [6] (Figure 2). On standardized outlet views, the acromion morphology was classified according to Bigliani and Morrison into type I (flat), type II (curved), and type III (hooked). [2]

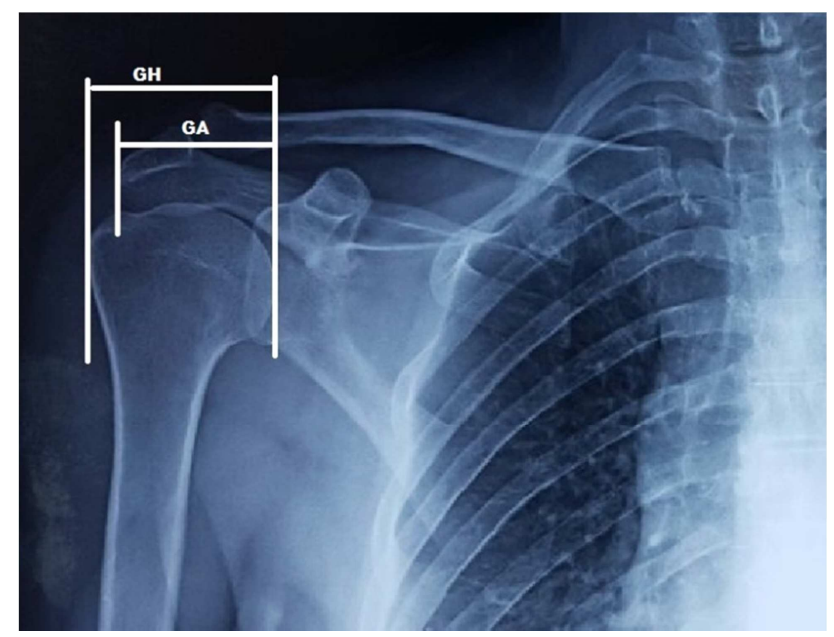

\begin{tabular}{|c|c|c|c|c|c|}
\hline Patients & Age & Sex & Bigliani & IA & CSA \\
\hline 6 & 39 & $\mathrm{H}$ & 3 & 0,73 & 36 \\
\hline 7 & 47 & $\mathrm{H}$ & 1 & 0,58 & 33 \\
\hline 8 & 38 & $\mathrm{~F}$ & 3 & 0,7 & 38 \\
\hline 9 & 60 & $\mathrm{H}$ & 3 & 0,78 & 39 \\
\hline 10 & 59 & $\mathrm{H}$ & 3 & 0,8 & 39 \\
\hline 11 & 65 & $\mathrm{H}$ & 3 & 0,7 & 38 \\
\hline 12 & 59 & $\mathrm{~F}$ & 2 & 0,76 & 39 \\
\hline 13 & 48 & $\mathrm{~F}$ & 3 & 0,67 & 35 \\
\hline 14 & 80 & $\mathrm{H}$ & 3 & 0,64 & 33 \\
\hline 15 & 75 & $\mathrm{H}$ & 3 & 0,65 & 34 \\
\hline 16 & 70 & $\mathrm{~F}$ & 2 & 0,67 & 38 \\
\hline 17 & 62 & $\mathrm{H}$ & 3 & 0,77 & 37 \\
\hline 18 & 55 & $\mathrm{H}$ & 3 & 0,75 & 39 \\
\hline 19 & 55 & $\mathrm{~F}$ & 2 & 0,78 & 38 \\
\hline 20 & 68 & $\mathrm{H}$ & 3 & 0,73 & 38 \\
\hline 21 & 42 & $\mathrm{H}$ & 3 & 0,59 & 33 \\
\hline 22 & 59 & $\mathrm{~F}$ & 3 & 0,73 & 38 \\
\hline 23 & 62 & $\mathrm{H}$ & 3 & 0,75 & 39 \\
\hline 24 & 36 & $\mathrm{H}$ & 3 & 0,71 & 37 \\
\hline 25 & 47 & $\mathrm{H}$ & 2 & 0,75 & 38 \\
\hline 26 & 57 & $\mathrm{H}$ & 3 & 0,65 & 39 \\
\hline 27 & 51 & $\mathrm{H}$ & 3 & 0,71 & 39 \\
\hline 28 & 66 & $\mathrm{H}$ & 2 & 0,73 & 38 \\
\hline 29 & 48 & $\mathrm{H}$ & 3 & 0,69 & 37 \\
\hline 30 & 50 & $\mathrm{~F}$ & 3 & 0,73 & 38 \\
\hline 31 & 39 & $\mathrm{H}$ & 3 & 0,73 & 39 \\
\hline 32 & 37 & $\mathrm{H}$ & 3 & 0,77 & 37 \\
\hline 33 & 48 & $\mathrm{H}$ & 2 & 0,65 & 36 \\
\hline 34 & 50 & $\mathrm{~F}$ & 3 & 0,73 & 38 \\
\hline 35 & 58 & $\mathrm{H}$ & 3 & 0,68 & 38 \\
\hline 36 & 69 & $\mathrm{H}$ & 3 & 0,73 & 38 \\
\hline 37 & 58 & $\mathrm{H}$ & 3 & 0,74 & 38 \\
\hline Average & \multicolumn{3}{|c|}{52,91892} & 0,702703 & 37 \\
\hline
\end{tabular}

Figure 1. Measuring of acromion index: GH: Glenohumeral Distance, GA: Glenoacromial Distance.

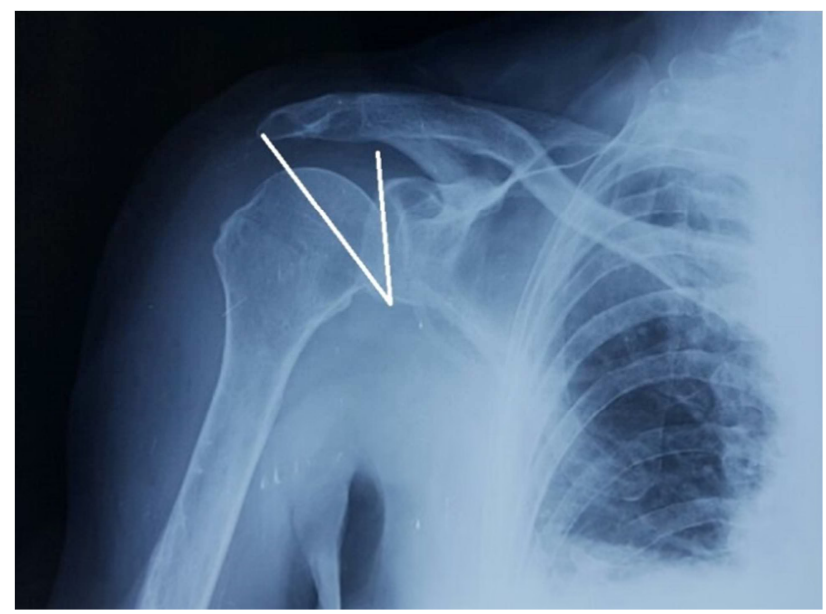

Figure 2. Measuring of critical shoulder angle.

\section{Results}

According to Bigliani and Morisson classification, acromion was flat (type 1$)$ in 2 patients (6\%), curve (type 2$)$ in eight patients $(22 \%)$, and hooked (type 3$)$. The mean acromial index was $0.7( \pm 0.057)$. The mean critical shoulder angle was $37^{\circ}( \pm 1.95)$. (Table)

Table 1. Radiologic assessment.

\begin{tabular}{llllll}
\hline Patients & Age & Sex & Bigliani & IA & CSA \\
\hline 1 & 27 & F & 3 & 0,68 & 37 \\
2 & 31 & H & 2 & 0,72 & 36 \\
3 & 45 & H & 1 & 0,62 & 34 \\
4 & 56 & H & 2 & 0,6 & 33 \\
5 & 42 & F & 3 & 0,6 & 35 \\
\hline
\end{tabular}

\section{Discussion}

The influence of individual scapular morphology on the pathogenesis of rotator cuff tears (RCTs) remains controversial. Although some authors place great importance on anatomic variants, particularly those of the acromion, other authors have suggested that these changes are the result of rather than the cause of degenerative rotator cuff disease. [7] - [10] So the pathogenesis of rotator cuff tears has been considered the result of a combination of intrinsic and extrinsic factors. Degenerative change [8], hypovascularity [11], and micro-structural collagen fibre abnormalities [12] are recognized as the intrinsic factors, and subacromial impingement [13], [14], tensile overload [15], and the repetitive use [16] are recognized as the extrinsic factors. Neer [1] Based on cadaveric dissection and intra-operative observation, introduced the term impingement syndrome to describe mechanical conflict between the anterior acromion and the rotator cuff. He attributed $95 \%$ of all RCTs to the pathological shape of the anterior acromion. Bigliani and Morrison [2] identified three distinct acromial shapes that were more or less likely to be associated with RCTs. Balke et al. [17] supported the finding that the hook acromion is the 
predisposing factor to degeneration of supraspinatus tendon by publishing that, compared to the control group, significant portion of patients with subacromial pathology had the hook acromion. However, the result of Jacobson et al. [18] and that of Zuckerman et al. [19] reported the poor intra- and interobserver agreement of this classification. Hamid et al. [20] also confirmed that Bigliani acromial morphology classification system lacked inter-observer reliability despite a standardized fashion with a precise radiographic protocol by specially trained staff. So although used in practice, this classification is controversial because of its high interobserver variability. This variability is due to the lack of a clear definition of the terms "flat", "hooked" and "curve" and to the random quality of radiographic images, which are particularly sensitive to minor variations in the cranio-caudal angulation of the x-ray tube. [21] Recently, Nyffeler et al. [5] introduced an acromion index. Which is measured by drawing three parallel lines and measuring the distances between those lines. The first line connected the superior and inferior osseous margins of the glenoid cavity. The second is tangential to the lateral border of the acromion, and the third line is tangential to the most lateral part of the proximal part of the humerus. The distance from the glenoid to the acromion was divided by the distance from the glenoid to the lateral aspect of the humeral head, and the resulting value was called the acromion index. Using a ratio rather than absolute values permits to avoid magnification errors on radiographic images and to compare individuals of different sizes. Since the introduction of the AI by Nyffeler in 2006, his concept was strengthened by the contribution of several studies. [17], [22] - [26] Torrens et al [25] confirmed the relationship between RCTs and a large coverage of the humeral head. Although those authors used a slightly modified technique to quantify the lateral extension of the acromion, their results were comparable to those of Nyffeler et al. A high AI was then found to be a risk factor for a retear after rotator cuff repair as well as an associated factor for progression of the tear size. Contrary to these findings, Hamid et al [20] found no association between a large lateral extension of the acromion and presence of rotator cuff disease. Xinyu Li [27] in a more recent three-dimensional analysis, find that the acromial morphological variation is related with subacromial impingement. Kim et al in an MRI study showed that a higher AI was detected more frequently in patients with large-to-massive rotator cuff tears than in patients with partial-thickness articular side tears on MRI. [22] In our study the AI was at mean 0.7 , which means the existence of an important lateral acromial overhang in the patients with RCTs. This result confirms that AI is an important parameter to consider in RCTs.

Moor [6] described the critical shoulder angle. This is an angle formed between the line from the lower edge of the glenoid to its upper edge and another line from the lower edge of the Glenoid at the lateral edge of the acromion. This angle combines the acromion index and the inclination of the glenoid fossa. According to the results of Moor's [6] study, this angle is between $30^{\circ}$ and $35^{\circ}$ in the population without
RCTs or osteoarthritis. He considers this as the better parameter to evaluate the lateral extension of the acromion and according to him; this must be taken into consideration in any treatment of RCTs. In Population with RCTs, this angle measures more than $35^{\circ}$. In another recent study, Moor demonstrated that there is an excellent correlation between the AI and CSA. His finding imply that the lateral extension of the acromion represents the more relevant risk factor for rotator cuff disease. [10] Garcia et al. In a retrospective study, make a postoperative ultrasound examination after arthroscopic repair of RCTs. They find that higher CSA significantly increased the risk of a full thickness rotator cuff retear after arthroscopic repair. But for Kirsch et al. [28] while the CSA is a strong radiographic predictor of rotator cuff pathology, it does not appear to have a predictive effect on outcomes after arthroscopic repair of atraumatic fullthickness tears.

In our study, we find that CSA is superior to $35^{\circ}$. Therefore, we confirm that high CSA is correlated with an important risk of rotator cuff tears.

\section{Conclusion}

Acromial morphology plays without any doubt an important role in the pathogenesis impingement and its evolution to cuff rotator tears. The results of our study confirm the importance of a more comprehensive evaluation of the morphology of the acromion, which take in consideration not only acromial shape, but especially its lateral extension evaluated by the acromial index and the critical angle of the shoulder. A larger comparative study is necessary to confirm these results.

\section{References}

[1] Neer CS 2nd (1972) Anterior acromioplasty for the chronic impingement syndrome in the shoulder: a preliminary report. J Bone Joint Surg Am 54 (1): 41-50.

[2] Bigliani LU, Morrison DS, April EW (1986) The morphology of the acromion and its relationship to rotator cuff tears. Orthop Trans 10: 228.

[3] Aoki M, Ishii S, Usui M (1986) The slope of the acromion and rotator cuff impingement. Orthop Trans 10: 228.

[4] Banas MP, Miller RJ, Totterman S (1995) Relationship between the lateral acromion angle and rotator cuff disease. $\mathrm{J}$ Should Elbow Surg 4 (6): 454-461.

[5] Nyffeler RW, Werner CM, Sukthankar A, Schmid MR, Gerber C. Association of a large lateral extension of the acromion with rotator cuff tears. J Bone Joint Surg Am. 2006 Apr; 88 (4): 800-5.

[6] Moor BK, Bouaicha S, Rothenfluh DA, Sukthankar A, Gerber C. Is there an association between the individual anatomy of the scapula and the development of rotator cuff tears or osteoarthritis of the glenohumeral joint?: A radiological study of the critical shoulder angle. Bone Joint J. 2013 Jul; 95-B (7): 935-41. 
[7] Nicholson GP, Goodman DA, Flatow EL, Bigliani LU. The acromion: morphologic condition and age-related changes. A study of 420 scapulas. J Shoulder Elbow Surg 1996; 5:1-11.

[8] Ozaki J, Fujimoto S, Nakagawa Y, Masuhara K, Tamai S. Tears of the rotator cuff of the shoulder associated with pathological changes in the acromion.A study in cadavera. $\mathrm{J}$ Bone Joint SurgAm 1988; 70: 1224-30.

[9] Wang JC, Shapiro MS. Changes in acromial morphology with age. J Shoulder Elbow Surg 1997; 6: 55-9.

[10] Moor BK, Wieser K, Slankamenac K, Gerber C, Bouaicha S. Relationship of individual scapular anatomy and degenerative rotator cuff tears. Shoulder Elbow Surg. 2014 Apr; 23 (4): 536-41.

[11] Chansky HA, Iannotti JP (1991) The vascularity of the rotator cuff. Clin Sports Med 10 (4): 807-822.

[12] Nixon JE, DiStefano V (1975) Ruptures of the rotator cuff. Orthop Clin North Am 6 (2): 423-447.

[13] Bigliani LU, Ticker JB, Flatow EL, Soslowsky LJ, Mow VC (1991) Relationship of acromial architecture and diseases of the rotator cuff. Orthopade 20 (5): 302-309.

[14] Toivonen DA, Tuite MJ, Orwin JF (1995) Acromial structure and tears of the rotator cuff. J Should Elbow Surg 4 (5): 376383 .

[15] Hayes PR, Flatow EL (2002) Attrition sign in impingement syndrome. Arthroscopy 18 (9): E44.

[16] Ouellette H, Labis J, Bredella M, Palmer WE, Sheah K, Torriani M (2008) Spectrum of shoulder injuries in the baseball pitcher. Skeletal Radiol 37 (6): 491-498. doi:10.1007/s00256-007-0389-0.

[17] Balke M, Schmidt C, Dedy N, Banerjee M, Bouillon B, Liem D (2013) Correlation of acromial morphology with impingement syndrome and rotator cuff tears. Acta Orthop 84 (2), 178-183.

[18] Jacobson SR, Speer KP, Moor JT, Janda DH, Saddemi SR, MacDonald PB, Mallon WJ (1995) Reliability of radiographic assessment of acromial morphology. J Shoulder Elbow Surg 4 (6), 449-453.
[19] Zuckerman JD, Kummer FJ, Cuomo F, Greller M (1997) Interobserver reliability of acromial morphology classification: an anatomic study. J Shoulder Elbow Surg 6, 286-287.

[20] Hamid N, Omid R, Yamaguchi K, Keener JD (2012) Relationship of radiographic acromial characteristics and rotator cuff disease: a prospective investigation of clinical, radiographic, and sonographic findings. J Shoulder Elbow Surg 21 (10), 1289-1298.

[21] A Denis, J Vial, N Sans, O Loustau, H Chiavassa-Gandois et J-J Railhac Radiographies de l'épaule: les incidences utiles en pratique courante. J Radiol 2008; 89: 620-32.

[22] Kim JR, Ryu KJ, Hong IT, Kim BK, Kim JH. Can a high acromion index predict rotator cuff tears? Int Orthop 2012; 36: 1019-24.

[23] Miyazaki AN, Itoi E, Sano H, Fregoneze M, Santos PD, da Silva LA, et al. Comparison between the acromion index and rotator cuff tears in the Brazilian and Japanese populations. J Shoulder Elbow Surg 2011; 20: 1082-6.

[24] Musil D, Sadovsky P, Rost M, Stehlik J, Filip L. Relationship of acromial morphology and rotator cuff tears. Acta Chir Orthop Traumatol Cech 2012; 79: 238-42.

[25] Torrens C, Lopez JM, Puente I, Caceres E. The influence of the acromial coverage index in rotator cuff tears. J Shoulder Elbow Surg 2007; 16: 347-51.

http://dx.doi.org/10.1016/j.jse.2006.07.006.

[26] Zumstein MA, Jost B, Hempel J, Hodler J, Gerber C. The clinical and structural long-term results of open repair of massive tears of the rotator cuff. J Bone Joint Surg Am 2008; 90:2423-31. http://dx.doi.org/10.2106/JBJS.G.00677.

[27] Li X et al. Relationship between acromial morphological variation and subacromial impingement: A three-dimensional analysis. PLoS One. 2017 Apr 25; 12 (4): e0176193. doi:10.1371/journal.pone.0176193.

[28] Kirsch JM, Nathani A, Robbins CB, Gagnier JJ, Bedi A, Miller BS. Is There an Association Between the "Critical Shoulder Angle" and Clinical Outcome After Rotator Cuff Repair? Orthop J Sports Med. 2017 Apr 18; 5 (4): 2325967117702126. doi: 10.1177/2325967117702126. 